\title{
Estresse hídrico e salino em sementes de soja classificadas em diferentes tamanhos ${ }^{1}$
}

\author{
Marcos Morais Soares ${ }^{2}$, Hamilton Carvalho dos Santos Junior ${ }^{3}$, \\ Mateus Geraldo Simões ${ }^{3}$, Dalcionei Pazzin ${ }^{3}$, Laércio Junio da Silva ${ }^{3}$
}

\begin{abstract}
Water and salt stress in soybean seeds classified in different sizes

The importance of seed size has been reported for many species, since it may affect seed germination and seedling vigor, especially under stress conditions. This study aimed at evaluating the effect of seed size on the germination and initial growth of soybean seedlings (M9144RR and M8527RR cultivars), under water and salt stress conditions. Water stress was induced by mannitol and salt stress by sodium chloride. The seeds were submitted to the germination test, first germination count and seedling growth to assess the effects of the treatments. A completely randomized design with four replications was used. The germination and vigor of soybean seeds decreased with the reduction of osmotic potential. There was no effect of seed size on germination and seedlings length. However, the seeds with higher size resulted in seedlings with greater dry mass, even when subjected to water and salt stress conditions.
\end{abstract}

KEY-WORDS: Glycine max; water potential; seed quality.

\section{INTRODUÇÃO}

O avanço da área de cultivo de soja vem ocorrendo em todas as regiões do País (Conab 2014), especialmente no Nordeste, que possui a maior concentração de solos salinos e baixos índices pluviométricos (Cirilo et al. 2010).

Os solos salinizados ocorrem em condições topográficas que não favorecem uma drenagem eficiente, principalmente onde o manejo da irrigação é inadequado ou a água utilizada apresenta problemas de qualidade (Oliveira 1997).

A salinidade do solo pode comprometer a germinação das sementes pela diminuição do potencial osmótico externo, impedindo a absorção de água, ou por meio dos efeitos tóxicos da absorção de íons

\section{RESUMO}

A importância do tamanho das sementes tem sido relatada para várias espécies, visto que pode afetar a sua germinação e o vigor das plântulas, principalmente sob condições de estresse. Objetivou-se avaliar o efeito do tamanho das sementes na germinação e crescimento inicial de plântulas de soja (cultivares M9144RR e M8527RR), sob condições de estresse hídrico e salino. O estresse hídrico foi induzido por manitol e o salino por cloreto de sódio. Para a avaliação do efeito dos tratamentos, as sementes foram submetidas ao teste de germinação, primeira contagem de germinação e crescimento de plântulas. Utilizou-se delineamento inteiramente casualizado, com quatro repetições. Houve redução na germinação e no vigor das sementes de soja com a diminuição do potencial osmótico. Não foi observado efeito do tamanho das sementes sobre a germinação e comprimento das plântulas, porém, as sementes de maior tamanho resultaram em plântulas com maior massa seca, mesmo quando submetidas a condições de estresse hídrico e salino.

PALAVRAS-CHAVE: Glycine max; potencial hídrico; qualidade de sementes.

como o $\mathrm{Na}^{+}$e o $\mathrm{Cl}^{-}$(Murillo-Amador et al. 2002, Khajeh-Hosseini et al. 2003). Os íons e o estresse osmótico são responsáveis tanto pela inibição quanto pela demora na germinação e estabelecimento das plântulas (Almansouri et al. 2001). Se comparado ao estresse salino, o problema da seca é ainda mais abrangente e economicamente muito prejudicial à agricultura (Pimentel 1999).

Para a cultura da soja, os estresses salino e hídrico provocam efeitos negativos na germinação e vigor das sementes e, em condições de estresses ainda mais severas, as sementes de menor vigor são as mais suscetíveis (Braccini et al. 1996).

Em diversos trabalhos tem sido avaliado o efeito do estresse hídrico induzido por $\mathrm{NaCl}$ na germinação e no crescimento de plântulas (Braccini 
et al. 1996, Machado Neto et al. 2006, Coelho et al. 2010). Além do $\mathrm{NaCl}$, o manitol tem sido comumente utilizado como agente osmótico para simular condições de déficit hídrico, porque é um composto quimicamente inerte e não tóxico.

Braccini et al. (1996) verificaram que o uso de solução de manitol para simular condições de baixa umidade no solo apresentou resultados satisfatórios com sementes de soja, enquanto Machado Neto et al. (2006) obtiveram êxito na utilização de soluções de manitol com diferentes potenciais osmóticos, como simuladores de deficiência hídrica, em sementes de feijão.

Um dos fatores que pode ter influência no vigor das sementes é o seu tamanho. Nesse sentido, alguns estudos demonstram que sementes de soja de maior tamanho, quando comparadas às de menor tamanho, apresentam qualidade fisiológica superior (Santos et al. 2005, Pádua et al. 2010). Contudo, esses resultados não são unânimes (Perin et al. 2002, Ávila et al. 2008, Camozzato et al. 2009, Piccinin et al. 2012). Além disso, a preferência por sementes de menor tamanho tem sido uma prática comum entre os agricultores, devido à economia com o tratamento, transporte e aquisição das mesmas, visto que são comercializadas por peso (Krzyzanowski et al. 1999).

Sementes pequenas possuem uma relação de superfície/volume maior do que as grandes, o que facilita a obtenção de água para iniciar o processo de germinação, no entanto, apresentam menor quantidade de reservas (Kopper et al. 2010). Os efeitos do tamanho das sementes na germinação e no vigor das plântulas, em condições de estresse hídrico e salino, ainda são controversos, principalmente na cultura da soja (Grieve \& Francois 1992, Costa et al. 2004, Kaya et al. 2008).

Objetivou-se avaliar o efeito do tamanho das sementes na germinação e no crescimento de plântulas de soja, sob condições de estresse salino e hídrico.

\section{MATERIAL E MÉTODOS}

O experimento foi conduzido no Laboratório de Pesquisa de Sementes do Departamento de Fitotecnia da Universidade Federal de Viçosa, em Viçosa (MG), nos meses de março e abril de 2013. Foram utilizadas sementes de soja das cultivares M9144RR e M8527RR, classificadas em dois tamanhos: peneiras de $5,5 \mathrm{~mm}$ e $7,5 \mathrm{~mm}$, para a cultivar M9144RR; e peneiras de 5,5 $\mathrm{mm}$ e 7,0 mm, para a cultivar M8527RR.
As sementes foram submetidas ao teste de germinação e de crescimento de plântulas, sob condições de estresse hídrico e/ou salino, em dois ensaios. Foram testados oito tratamentos, que consistiram em diferentes potenciais osmóticos, induzidos por solução de manitol ou cloreto de sódio, mais um tratamento controle. No primeiro ensaio, foram testados quatro potenciais osmóticos induzidos por solução de manitol: - $0,3 \mathrm{MPa},-0,6 \mathrm{MPa},-0,9 \mathrm{MPa}$ e -1,2 MPa; e, no segundo, quatro potenciais induzidos por cloreto de sódio ( $\mathrm{NaCl}$ ): -0,1 MPa, -0,3 MPa, -0,6 MPa e -0,9 MPa. $\mathrm{O}$ tratamento controle $(0,0 \mathrm{MPa})$, que consistiu no uso de água destilada, foi comum aos dois ensaios.

As concentrações de manitol para obtenção dos potenciais osmóticos foram determinadas pela equação de Van't Hoff, ou seja, yos = -RTC, em que: yos = potencial osmótico $(\mathrm{atm}) ; \mathrm{R}=$ constante geral dos gases perfeitos $\left(8,32 \mathrm{~J} \mathrm{~mol}^{-1} \mathrm{~K}^{-1}\right) ; \mathrm{T}=$ temperatura $(\mathrm{K})$; e $\mathrm{C}=$ concentração $\left(\mathrm{mol} \mathrm{L}^{-1}\right)$.

As concentrações de $\mathrm{NaCl}$ foram calculadas por meio da curva de calibração estabelecida por Braccini et al. (1996), ou seja, yos $=0,194699+$ 0,750394 C, em que: yos = potencial osmótico (bar); e $\mathrm{C}=$ concentração $\left(\mathrm{g} \mathrm{L}^{-1}\right)$.

O teste de germinação foi conduzido com quatro subamostras de 50 sementes cada. As sementes foram semeadas sobre duas folhas de papel germitest umedecido com volume de solução composta por cada sal, equivalente a 2,5 vezes o peso do substrato seco, nos diferentes potenciais osmóticos, e, em seguida, foram cobertas com mais uma folha. Posteriormente, foram confeccionados rolos e esses foram mantidos em germinador (modelo Mangelsdorf), à temperatura de $25 \pm 1{ }^{\circ} \mathrm{C}$. As avaliações foram realizadas no quinto e oitavo dias após a semeadura, com o registro da porcentagem de plântulas normais (Brasil 2009).

Para o teste de primeira contagem de germinação, foram utilizados os dados de porcentagem de plântulas normais no quinto dia após a instalação do teste de germinação.

Para o teste de crescimento de plântulas, foram utilizadas quatro subamostras de 10 sementes cada. As sementes foram colocadas para germinar conforme a metodologia adotada para o teste de germinação, sendo semeadas na parte superior do rolo e mantidas em germinador, à temperatura de $25 \pm 1{ }^{\circ} \mathrm{C}$. As avaliações foram realizadas no oitavo dia após a semeadura e consistiram na determinação do comprimento e massa seca da parte aérea e da raiz primária das plântulas. 
Para avaliar o comprimento de plântulas, determinou-se o comprimento da parte aérea e da raiz primária, com o auxílio de régua graduada em milímetros, sendo os resultados expressos em centímetros por plântula.

Para determinar a massa seca de plântulas, as plântulas foram seccionadas em parte aérea e raiz primária e colocadas para secar em estufa com circulação forçada de ar, a $70{ }^{\circ} \mathrm{C}$, onde permaneceram até atingirem peso constante. Os resultados foram expressos em gramas por plântula.

O experimento foi conduzido em delineamento inteiramente casualizado, em esquema fatorial $2 \times 2 \times 5$, ou seja, duas cultivares (M9144RR e M8527RR), dois tamanhos de sementes $(5,5 \mathrm{~mm}$ e 7,5 mm; ou $5,5 \mathrm{~mm}$ e $7,0 \mathrm{~mm}$ ) e cinco potenciais osmóticos (manitol: 0,0 MPa, -0,3 $\mathrm{MPa},-0,6 \mathrm{MPa}$, $-0,9 \mathrm{MPa}$ e -1,2 $\mathrm{MPa}$; $\mathrm{NaCl}: 0,0 \mathrm{Mpa},-0,1 \mathrm{MPa}$, $-0,3 \mathrm{MPa},-0,6 \mathrm{MPa}$ e -0,9 $\mathrm{MPa}$ ), com quatro repetições, que consistiram nas subamostras dos testes.

Os dados foram analisados separadamente para os sais manitol e cloreto de sódio. As pressuposições de normalidade e homogeneidade de variância dos dados obtidos foram avaliadas por meio dos testes de Shapiro-Wilk e de Hartley, não sendo necessária a transformação dos dados. Os dados foram submetidos à análise de variância e as médias obtidas para o tamanho das sementes comparadas pelo teste F, a $5 \%$. Já as médias obtidas para os potenciais osmóticos foram submetidas à análise de regressão. As estimativas dos parâmetros da regressão foram analisadas pelo teste t, a $5 \%$.

\section{RESULTADOS E DISCUSSÃO}

A germinação e primeira contagem de germinação das sementes das duas cultivares foram afetadas negativamente pela redução no potencial osmótico, tanto sob condições de estresse hídrico (manitol) quanto de estresse hídrico e salino $(\mathrm{NaCl})$, independentemente do tamanho da semente (Figuras 1 e 2). Esses resultados estão de acordo com os obtidos por outros autores para sementes de soja
'M9144RR'

A

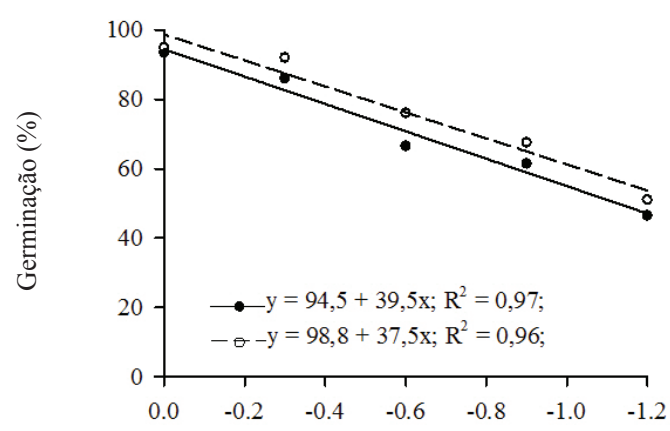

C

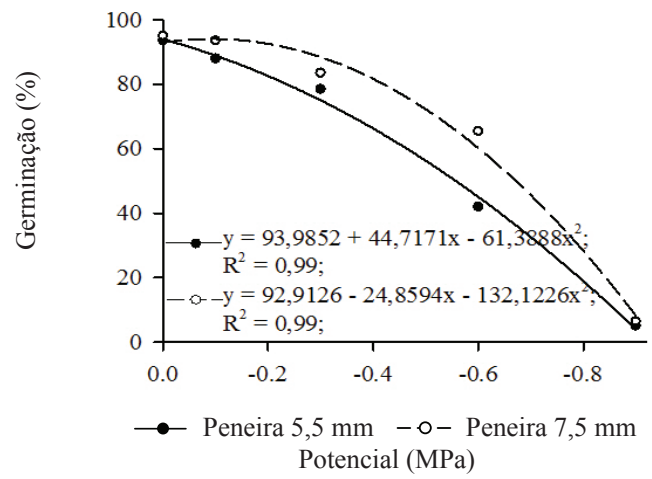

'M8527RR'

Manitol

B
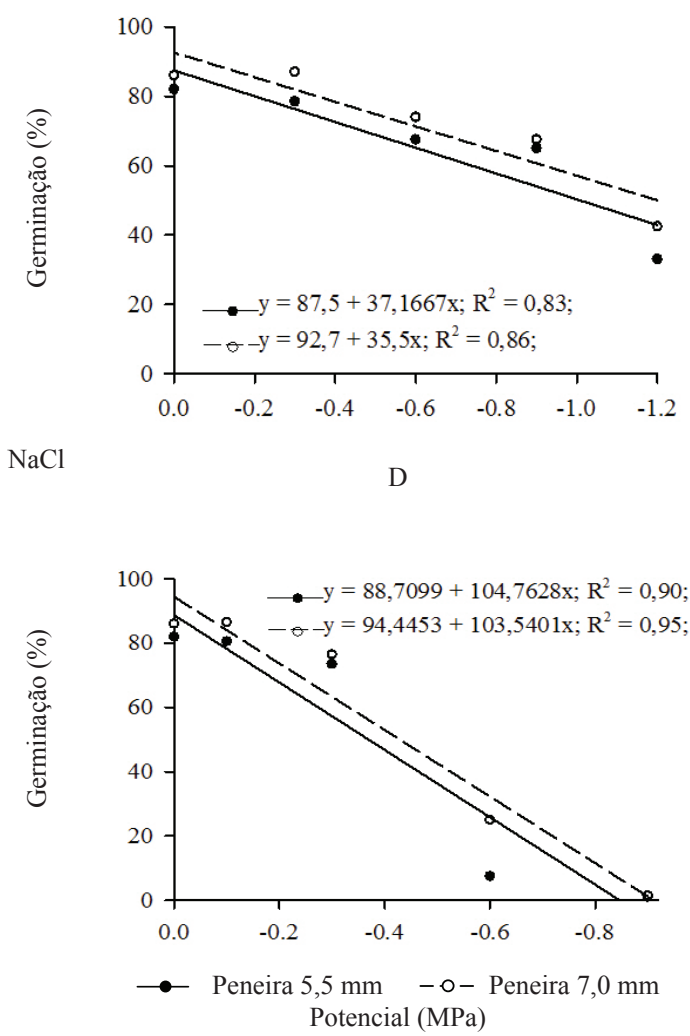

Figura 1. Germinação de sementes de soja de dois tamanhos, das cultivares M9144RR (A e C) e M8527RR (B e D), em função do potencial osmótico induzido por manitol (A e B) e cloreto de sódio ( $\mathrm{NaCl}$ ) (C e D) (Viçosa, MG, 2013). 

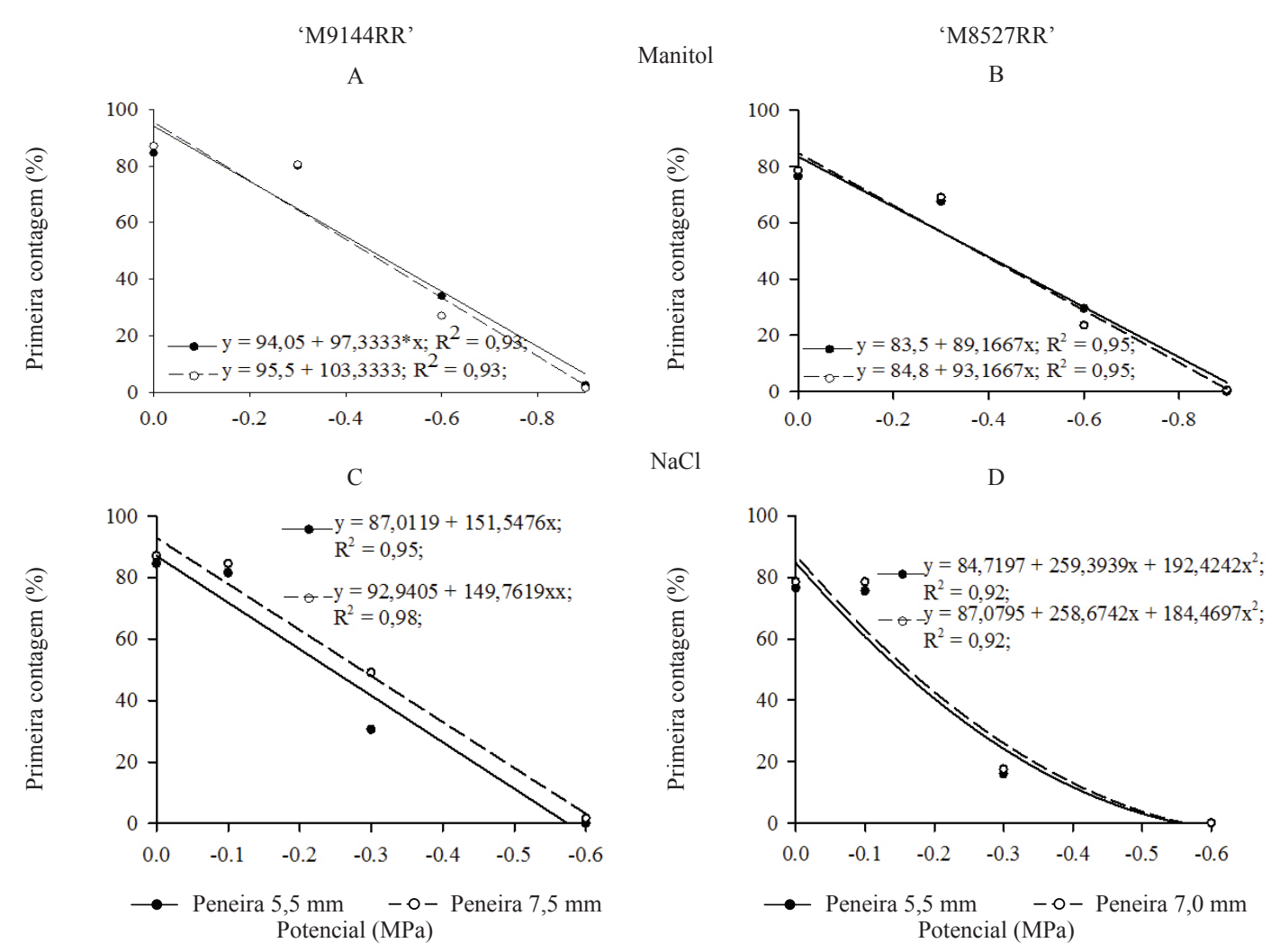

Figura 2. Primeira contagem do teste de germinação de sementes de soja de dois tamanhos, das cultivares M9144RR (A e C) e M8527RR (B e D), em função do potencial osmótico induzido por manitol (A e B) e NaCl (C e D) (Viçosa, MG, 2013).

(Braccini et al. 1996, Costa et al. 2004), bem como para outras culturas, como o milho-pipoca (Moterle et al. 2006), feijão (Machado Neto et al. 2006) e canola (Ávila et al. 2007). A redução na germinação das sementes sob estresse hídrico, ou seja, sob baixos potenciais hídricos, se deve à redução na disponibilidade de água necessária para a ativação e manutenção do metabolismo das sementes (Bewley et al. 2013).

A germinação das sementes, independentemente da cultivar e do tamanho, foi mais afetada pela redução no potencial osmótico induzido por $\mathrm{NaCl}$, em comparação ao manitol. Isso pode ser atribuído ao acúmulo de $\mathrm{Na}^{+}$, que altera o equilíbrio de íons e a disponibilidade de nutrientes minerais, reduzindo a divisão celular e o desenvolvimento do embrião (Moss \& Hoffman 1977, Mer et al. 2000). Contudo, em sementes de Urochloa, o estresse hídrico induzido por polietilenoglicol foi mais severo que o estresse induzido por $\mathrm{NaCl}$, nos mesmos potenciais (Pereira et al. 2012). Com isso, podemos afirmar que a germinação das sementes pode ser severamente afetada pela baixa disponibilidade de água, principalmente em solos que apresentam maiores teores de sais.
O tamanho das sementes não afetou a germinação e a primeira contagem (Figuras 1 e 2). Para algumas espécies, como o grão-de-bico, as sementes menores apresentam maior tolerância ao estresse hídrico provocado por $\mathrm{NaCl}$ (Kaya et al. 2008). Já para sementes de soja, as de menor tamanho, inicialmente, apresentam maior percentual de germinação, porém, essa diferença não é mantida com a redução no potencial osmótico (Costa et al. 2004).

Os comprimentos da parte aérea e da raiz primária foram afetados negativamente com a redução no potencial osmótico (Figuras 3 e 4). Segundo Kramer (1974), a redução no crescimento das plântulas, provocado pelo estresse hídrico, é causada pela redução da expansão celular. Ao reduzir a pressão de turgor, o estresse hídrico suprime a expansão e o crescimento celular, afetando o metabolismo, crescimento e estabelecimento das plântulas (Jaleel et al. 2009). A redução no crescimento das plântulas, além da soja (Moraes \& Menezes 2003, Costa et al. 2004, Teixeira et al. 2008), foi observado em outras culturas, como cevada (Anjum et al. 2003), canola (Ávila et al. 2007) e feijão (Machado Neto et al. 2006). 

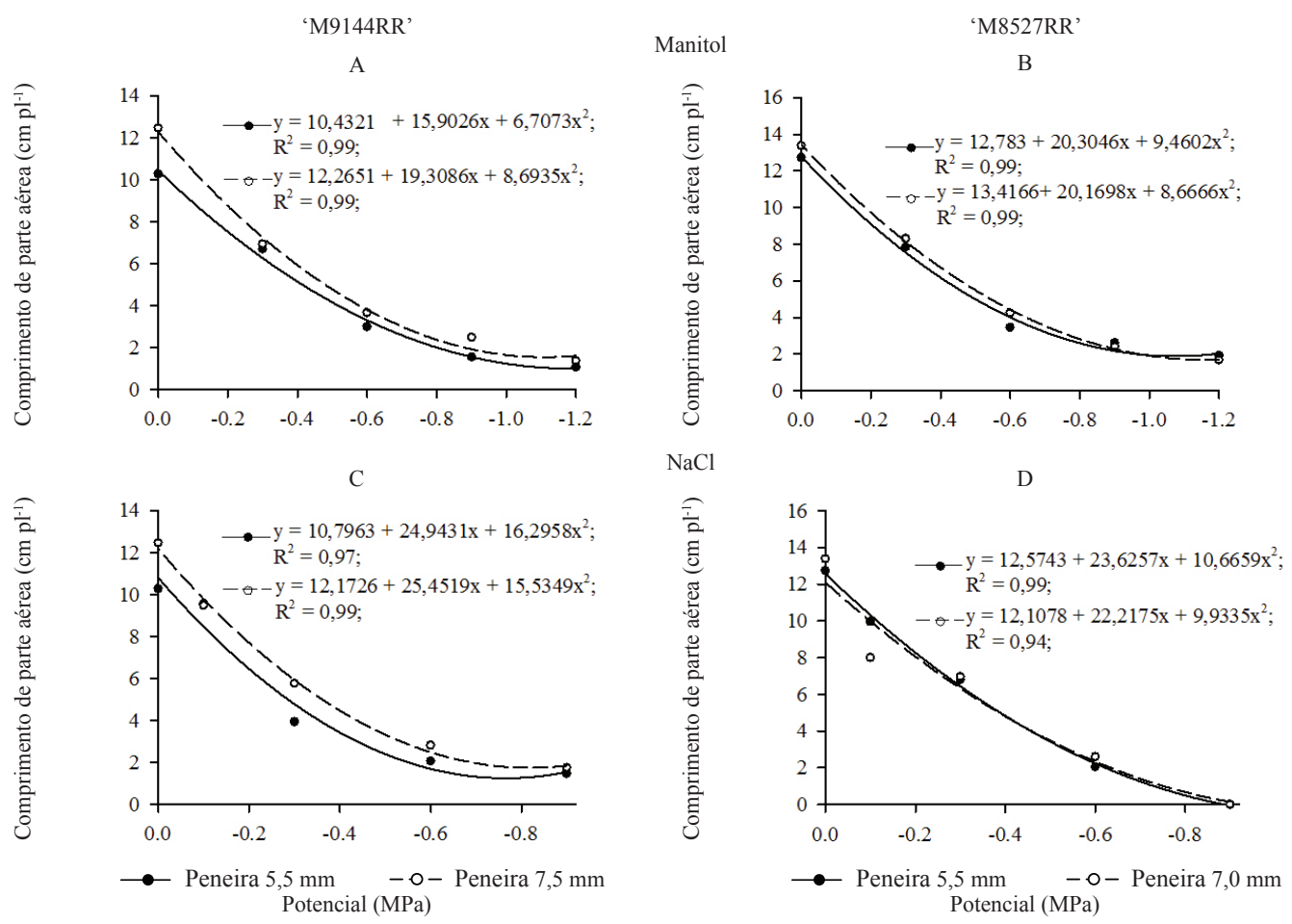

Figura 3. Comprimento da parte aérea de plântulas de soja oriundas de sementes de dois tamanhos, das cultivares M9144RR (A e C) e M8527RR (B e D), em função do potencial osmótico induzido por manitol (A e B) e cloreto de sódio $(\mathrm{NaCl})(\mathrm{C}$ e D) (Viçosa, MG, 2013).
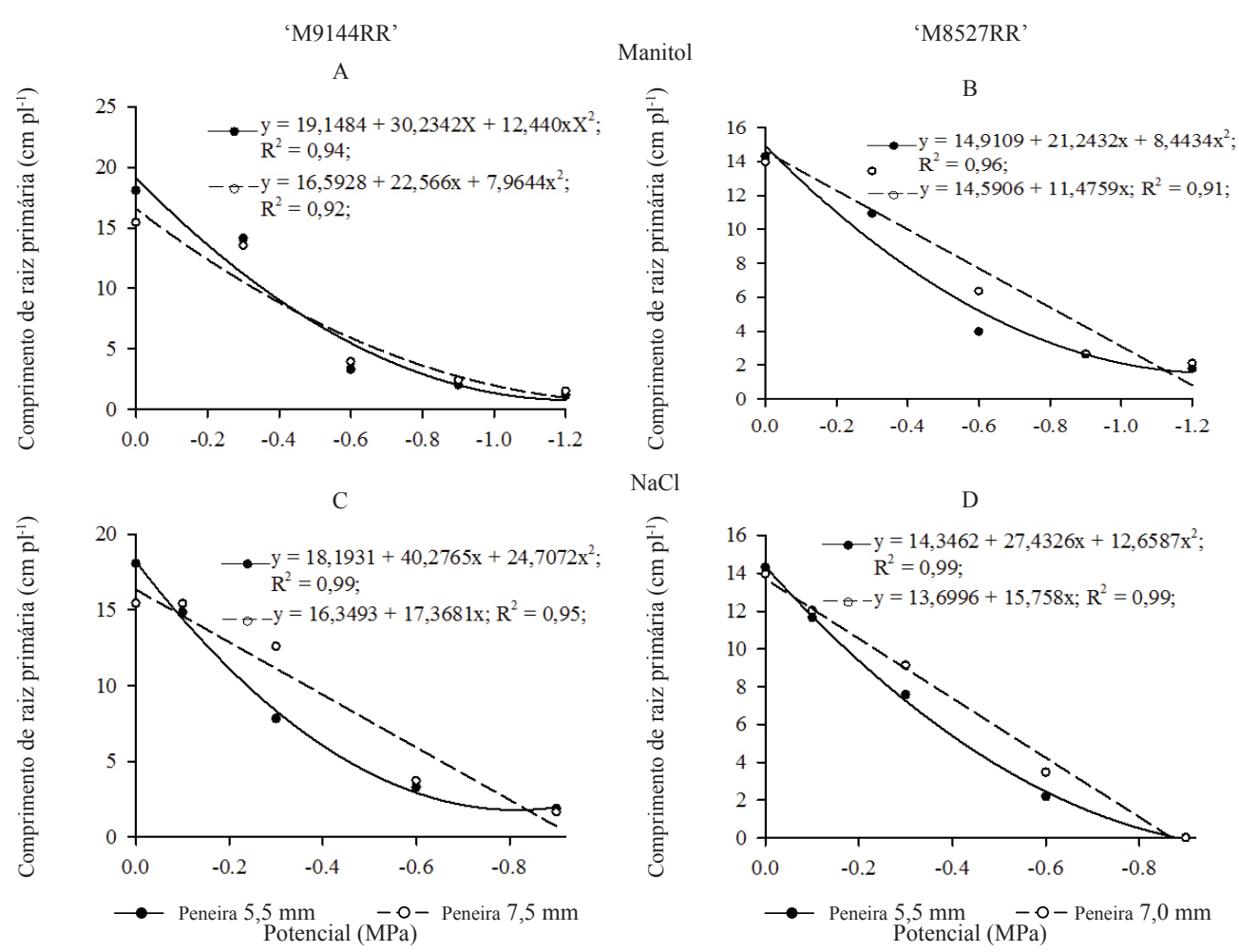

Figura 4. Comprimento da raiz primária de plântulas de soja oriundas de sementes de dois tamanhos, das cultivares M9144RR (A e C) e M8527RR (B e D), em função do potencial osmótico induzido por manitol (A e B) e cloreto de sódio $(\mathrm{NaCl})(\mathrm{C}$ e D) (Viçosa, MG, 2013). 
O comprimento da raiz primária reduziu-se à medida que diminuiu o potencial osmótico. Nas sementes de menor tamanho (peneira de 5,5 $\mathrm{mm}$ ), houve tendência de essa redução ser mais expressiva nos potenciais intermediários $(-0,2 \mathrm{a}-1,0 \mathrm{MPa})$, exceto nas sementes da cultivar M9144RR, sob estresse de manitol (Figura 4A). Esse resultado pode estar relacionado ao fato de que as sementes de menor tamanho, quando comparadas às maiores, possuem superfície maior, em relação ao seu volume, facilitando a absorção de água e, consequentemente, de $\mathrm{NaCl}$, o qual apresenta efeitos tóxicos (Khajeh-Hosseini et al. 2003).

Os estresses salino e hídrico também afetam negativamente a mobilização de reservas da semente para a plântula (Soltani et al. 2006), enquanto o estresse hídrico, em sementes menores, afeta negativamente a transferência das reservas, que já são limitadas, reduzindo o crescimento e desenvolvimento da plântula.

A redução no potencial osmótico induzido por manitol não afetou o acúmulo de massa seca da parte aérea das plântulas (Figura 5). Porém, quando submetidas ao estresse por $\mathrm{NaCl}$, foi observada re- dução no crescimento aéreo de ambas as cultivares, independentemente dos tamanhos das sementes. Em geral, foi observada maior massa seca da parte aérea das plântulas oriundas de sementes de maior tamanho, para as duas cultivares, tanto sob condições de estresse hídrico (manitol) quanto de estresse hídrico e salino $(\mathrm{NaCl})$ (Figura 5).

A massa seca da raiz primária das plântulas de soja das cultivares M9144RR e M8527RR foi reduzida com a redução no potencial osmótico (Figura 6). As plântulas oriundas de sementes com maior tamanho (peneiras de 7,0 $\mathrm{mm}$ e $7,5 \mathrm{~mm}$ ) apresentaram maior acúmulo de massa seca de raiz primária, quando comparadas às de menor tamanho. Esse efeito negativo do estresse hídrico na massa seca de plântulas também foi verificado por Costa et al. (2004). Contudo, esses autores não verificaram efeito do tamanho das sementes para esse parâmetro.

As sementes de maior tamanho, para as duas cultivares estudadas, apresentaram maior acúmulo de biomassa da parte aérea e da raiz primária em ambos os estresses, quando comparadas às sementes de me-

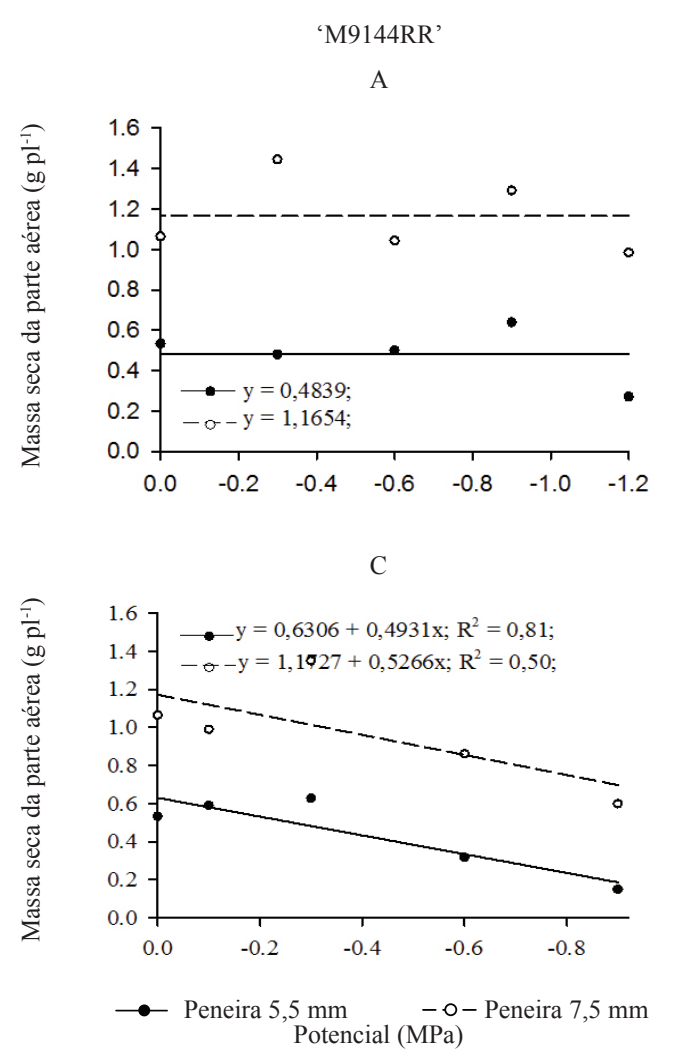

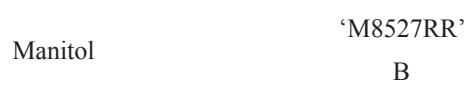

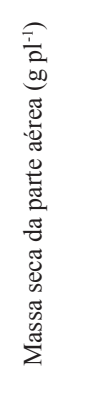

$\mathrm{NaCl}$

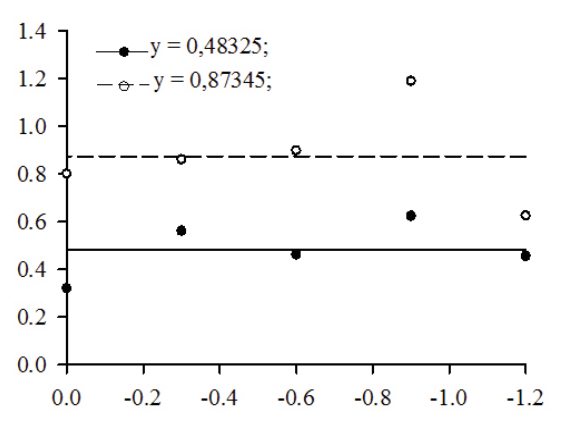

D

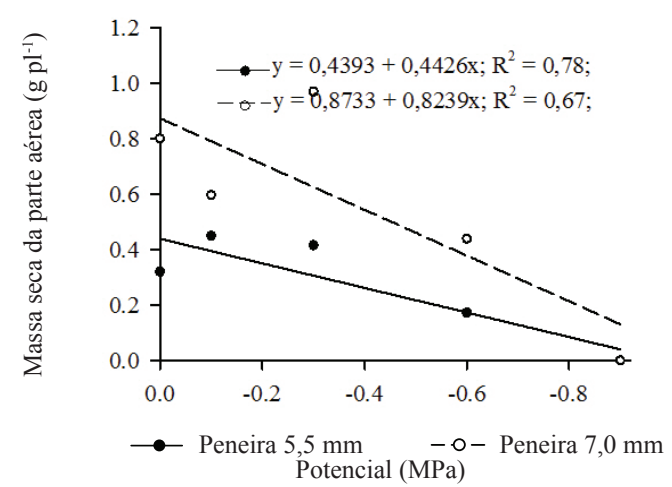

Figura 5. Massa seca da parte aérea de plântulas de soja oriundas de sementes de dois tamanhos, das cultivares M9144RR (A e C) e M8527RR (B e D), em função do potencial osmótico induzido por manitol (A e B) e cloreto de sódio $(\mathrm{NaCl})(\mathrm{C}$ e D) (Viçosa, MG, 2013). 


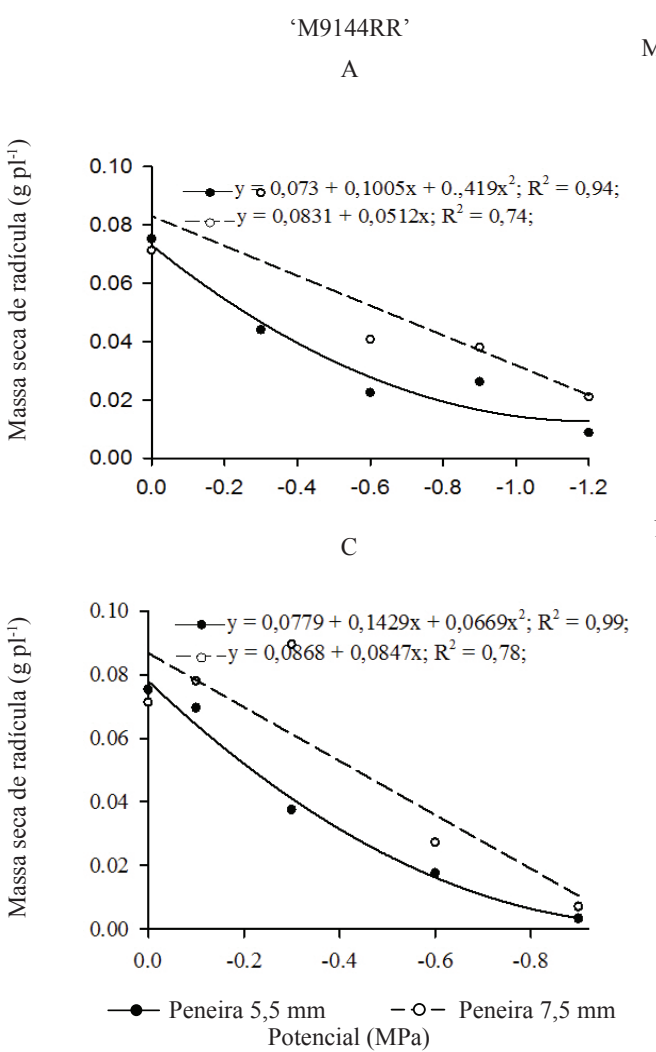

'M8527RR'
Manitol $\quad$ B
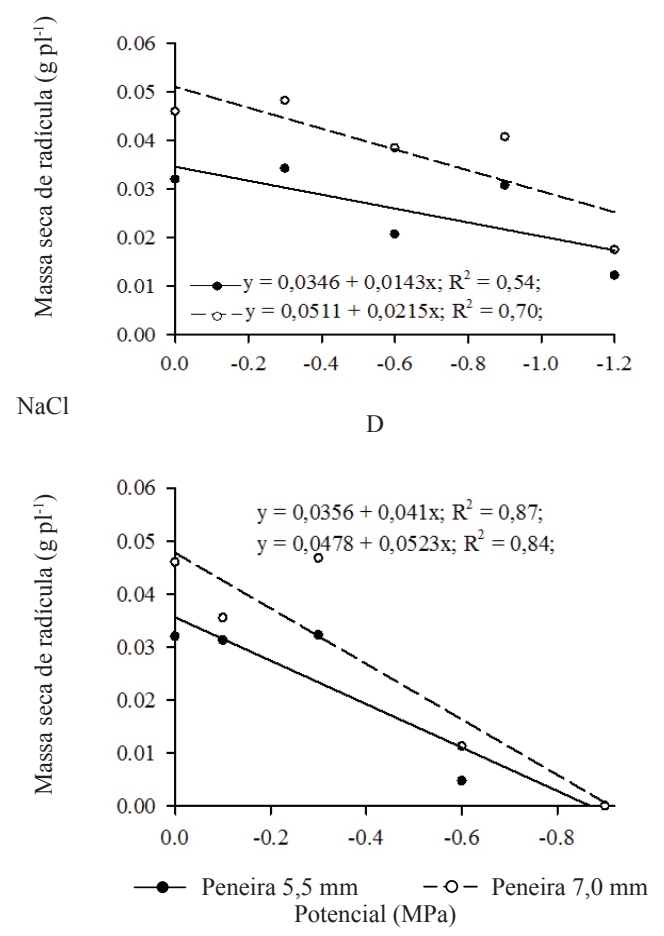

Figura 6. Massa seca de radícula de plântulas de soja oriundas de sementes de dois tamanhos, das cultivares M9144RR (A e C) e M8527RR (B e D), em função do potencial osmótico induzido por manitol (A e B) e cloreto de sódio $(\mathrm{NaCl})(\mathrm{C}$ e D) (Viçosa, MG, 2013).

nor tamanho. Esses resultados podem ser atribuídos à maior quantidade de reservas acumuladas pelas sementes maiores, as quais são transferidas para a plântula (Carvalho \& Nakagawa 2012).

Em geral, com a redução do potencial osmótico, houve redução na germinação e no vigor, avaliado por meio do teste de primeira contagem de germinação das sementes, independentemente do tamanho e da cultivar avaliada. $\mathrm{O}$ efeito detrimental causado pela redução no potencial osmótico é agravado pelo estresse salino de $\mathrm{NaCl}$. Além disso, houve redução no tamanho das plântulas (Figura 3), sendo que a redução no comprimento da raiz primária foi mais acentuada nas sementes menores, independentemente da cultivar (Figura 4).

As plântulas oriundas de sementes de maior tamanho, para ambas as cultivares, apresentaram maior massa seca sob condições de estresse hídrico e salino (Figura 5). Com isso, em solos que apresentem déficit hídrico ou excesso de sais, sugere-se a utilização de sementes de soja com maior tamanho, visto que as mesmas seriam menos afetadas, em comparação às sementes de menor tamanho.

\section{CONCLUSÕES}

1. O tamanho das sementes de soja não afeta a germinação e o comprimento de plântulas, sob condições de estresse hídrico e salino $(\mathrm{NaCl})$, exceto para o comprimento da raiz primária, que é maior para plântulas provenientes de sementes maiores.

2. A germinação e o vigor das sementes de soja são reduzidos sob condições de estresse hídrico e salino induzidos por manitol e cloreto de sódio.

3. As sementes de soja de maior tamanho resultam em plântulas com maior massa seca, mesmo quando submetidas a condições de estresse hídrico e salino.

\section{REFERÊNCIAS}

ALMANSOURI, M. et al. Effect of salt and osmotic stresses on germination in durum wheat (Triticum durum Desf.). Plant and Soil, Crawley, v. 231, n. 2, p. 243-254, 2001. 
ANJUM, F. et al. Water stress in barley (Hordeum vulgare L.): I. Effect on morphological characters. Pakistan Journal of Agricultural Sciences, Faisalabad, v. 40, n. 1, p. 43-44, 2003.

ÁVILA, M. R. et al. Influência do estresse hídrico simulado com manitol na germinação de sementes e crescimento de plântulas de canola. Revista Brasileira de Sementes, Londrina, v. 29, n. 1, p. 98-106, 2007.

ÁVILA, W. et al. Influência do tamanho da semente na produtividade de variedades de soja. Revista Agrarian, Dourados, v. 1, n. 2, p. 83-89, 2008.

BEWLEY, J. D. et al. Seeds: physiology of development, germination and dormancy. 3. ed. New York: Springer, 2013.

BRACCINI, A. L. et al. Germinação e vigor de sementes de soja sob estresse hídrico induzido por soluções de cloreto de sódio, manitol e polietilenoglicol. Revista Brasileira de Sementes, Londrina, v. 18, n. 1, p. 10-16, 1996.

BRASIL. Ministério da Agricultura, Pecuária e Abastecimento. Regras para análise de sementes. Brasília, DF: MAPA/SDA/ACS, 2009.

CAMOZZATO, V. A. et al. Desempenho de cultivares de soja em função do tamanho das sementes. Revista Brasileira de Sementes, Londrina, v. 31, n. 1, p. 288-292, 2009.

CARVALHO, N. M.; NAKAGAWA, J. Semente: ciência, tecnologia e produção. Jaboticabal: Funep, 2012.

CIRILO, J. A. et al. A questão da água no semiárido brasileiro. In: BICUDO, C. E. de M. et al. (Orgs.). Águas do Brasil: análises estratégicas. São Paulo: Instituto de Botânica, 2010. p. 81-91.

COELHO, D. L. M. et al. Estresse hídrico com diferentes osmóticos em sementes de feijão e expressão diferencial de proteínas durante a germinação. Acta Scientiarum Agronomy, Maringá, v. 32, n. 3, p. 491-499, 2010.

COMPANHIA NACIONAL DE ABASTECIMENTO (Conab). Acompanhamento da safra brasileira de grãos. 2014. Disponível em: <www.conab.gov.br>. Acesso em: 04 mar. 2015.

COSTA, P. R. et al. Estresse hídrico induzido por manitol em sementes de soja de diferentes tamanhos. Revista Brasileira de Sementes, Londrina, v. 26, n. 1, p. 105-113, 2004.

GRIEVE, C. M.; FRANCOIS, L. E. The importance of initial seed size in wheat plant response to salinity. Plant and Soil, Crawley, v. 147, n. 2, p. 197-205, 1992.

JALEEL, C. A. et al. Drought stress in plants: a review on morphological characteristics and pigments composition. International Journal of Agriculture Biology, Faisalabad, v. 11, n. 1, p. 100-105, 2009.
KAYA, M. et al. Interaction between seed size and $\mathrm{NaCl}$ on germination and early seedling growth of some Turkish cultivars of chickpea (Cicer arietinum L.). Journal of Zhejiang University SCIENCE B, Hangzhou, v. 9, n. 5, p. 371-377, 2008.

KHAJEH-HOSSEINI, M. et al. The interaction between salinity stress and seed vigour during germination of soybean seeds. Seed Science and Technology, Bassersdorf, v. 31, n. 3, p. 715-725, 2003.

KOPPER, A. C. et al. Influência da temperatura e do substrato na germinação de sementes de Cariniana estrellensis (Raddi) Kuntze. Revista Brasileira de Sementes, Londrina, v. 32, n. 2, p. 160-165, 2010.

KRAMER, P. J. Fifty years of progress in water relations research. Plant Physiology, Waterbury, v. 54, n. 4, p. 463471, 1974.

KRZYZANOWSKI, F. C. et al. Vigor de sementes: conceitos e testes. Londrina: Abrates, 1999.

MACHADO NETO, N. B. et al. Deficiência hídrica induzida por diferentes agentes osmóticos na germinação e vigor de sementes de feijão. Revista Brasileira de Sementes, Londrina, v. 28, n. 1, p. 142-148, 2006.

MER, R. K. et al. Effect of salts on germination of seeds and growth of young plants of Hordeum vulgare, Triticum aestivum, Cicer arietinum and Brassica juncea. Journal of Agronomy and Crop Science, Malden, v. 185, n. 4, p. 209-217, 2000.

MORAES, G. A. F.; MENEZES, N. L. Desempenho de sementes de soja sob condições diferentes de potencial osmótico. Ciência Rural, Santa Maria, v. 33, n. 2, p. 219 226, 2003.

MOSS, D. N.; HOFFMAN, G. J. Analysis of crop salt tolerance data. In: SHAIN, I.; SHALHEVET, J. Soil salinity under irrigation: process and management. Berlin: Ecological, 1977. p. 258-271.

MOTERLE, L. M. et al. Germinação de sementes e crescimento de plântulas de cultivares de milho-pipoca submetidas ao estresse hídrico e salino. Revista Brasileira de Sementes, Londrina, v. 28, n. 3, p. 169-176, 2006.

MURILLO-AMADOR, B. et al. Comparative effects of $\mathrm{NaCl}$ and polyethylene glycol on germination, emergence and seedling growth of cowpea. Journal of Agronomy and Crop Science, Malden, v. 188, n. 4, p. 235-247, 2002.

OLIVEIRA, M. Gênese, classificação e extensão de solos afetados por sais. In: GHEYI, H. R. et al. Manejo e controle da salinidade na agricultura irrigada. Campina Grande: UFPB/SBEA, 1997. p. 1-35.

PÁDUA, G. P. et al. Influência do tamanho da semente na qualidade fisiológica e na produtividade da cultura da 
soja. Revista Brasileira de Sementes, Londrina, v. 23, n. 3, p. 9-16, 2010.

PEREIRA, M. R. R. et al. Influência do estresse hídrico e salino na germinação de Urochloa decumbens e Urochloa ruziziensis. Bioscience Journal, Uberlândia, v. 28, n. 4, p. 537-545, 2012.

PERIN, A. et al. Efeito do tamanho da semente na acumulação de biomassa e nutrientes e na produtividade do feijoeiro. Pesquisa Agropecuária Brasileira, Brasília, DF, v. 37, n. 12, p. 1711-1718, 2002.

PICCININ, G. G. et al. Relação entre o tamanho e a qualidade fisiológica e sanitária de sementes de soja. Revista Agrarian, Dourados, v. 5, n. 15, p. 20-28, 2012.
PIMENTEL, C. Relações hídricas em dois híbridos de milho sob dois ciclos de deficiência hídrica. Pesquisa Agropecuária Brasileira, Brasília, DF, v. 34, n. 11, p. 20212027, 1999.

SANTOS, P. M. et al. Efeito da classificação por tamanho da semente de soja na sua qualidade fisiológica durante o armazenamento. Acta Scientiarum Agronomy, Maringá, v. 27, n. 3, p. 395-402, 2005.

SOLTANI, A. et al. Seed reserve utilization and seedling growth of wheat as affected by drought and salinity. Environmental and Experimental Botany, Elmsford, v. 55, n. 1, p. 195-200, 2006.

TEIXEIRA, J. R. et al. Avaliação de cultivares de soja quanto à tolerância ao estresse hídrico em substrato contendo polietileno glicol. Acta Scientiarum Agronomy, Maringá, v. 30, n. 2, p. 217-223, 2008. 